\title{
Design of an Aperture-Coupled Frequency-Reconfigurable Microstrip Stacked Array Antenna for LTE and WiMAX Applications
}

\author{
N. Ramli, ${ }^{1}$ M. T. Ali, ${ }^{1}$ M. T. Islam, ${ }^{2}$ A. L. Yusof, ${ }^{1}$ S. Muhamud-Kayat, ${ }^{1}$ and A. A. Azlan ${ }^{1}$ \\ ${ }^{1}$ Antenna Research Group (ARG), Microwave Technology Centre (MTC), Faculty of Electrical Engineering (FKE), \\ Universiti Teknologi Mara (UiTM), 40450 Shah Alam, Selangor, Malaysia \\ ${ }^{2}$ Institute of Space Science (ANGKASA), Level 2, Faculty of Engineering and Built Environment Building, \\ Universiti Kebangsaan Malaysia (UKM), 43600 Bangi, Selangor, Malaysia
}

Correspondence should be addressed to N. Ramli; nurulazlina84@gmail.com

Received 14 January 2014; Accepted 30 March 2014; Published 1 June 2014

Academic Editors: S. K. Goudos and S. Rapuano

Copyright (C) 2014 N. Ramli et al. This is an open access article distributed under the Creative Commons Attribution License, which permits unrestricted use, distribution, and reproduction in any medium, provided the original work is properly cited.

The aim of this paper is to design a novel structure of a frequency-reconfigurable microstrip array antenna by using a combination of aperture-coupled and the stacked patch technology. The four sets of two different aperture slot shapes (I-shaped and H-shaped) are printed on the ground and are functional to transfer the wave and the signal to the selected radiating layers. Both aperture slot positions are based on the bottom patches (layer 2) and top patches (layer 1), respectively. To achieve the frequency reconfigurability, four PIN diode switches are integrated on the feed line layer positioned between both aperture slots on the ground. The activation of the selected patches will determine the current operating frequency of the proposed antenna. A $2.6 \mathrm{GHz}$ or $3.5 \mathrm{GHz}$ frequency is achieved by switching all the PIN diode switches to ON or OFF mode synchronously. The advantage of the proposed antenna is that it can minimize the usage of the antenna's surface area, with different size of the patch having different operating frequencies, sorted in different layer. The measured results of the return losses, radiation patterns, and the practical indoor propagation measurement achieved good agreement with the simulated results.

\section{Introduction}

Reconfigurable antenna has a significant potential in the modern wireless communication. This is as a result of the reduction in antenna size and cost and convenience for certain applications to operate with a single antenna compared to multiple antennas. Moreover, these reconfigurable antennas have interesting characteristics as they can provide various features in different operating frequencies [1-3], polarizations $[4,5]$, and radiation patterns $[6,7]$ by changing the current distribution over the volume of the antennas. Therefore, the switching circuit of the PIN diode switch, microelectromechanical switches (MEMs), varactor diodes, or other RF switches is embedded on the antennas to achieve reconfigurability. Thus, in this work, the PIN diode is chosen due to the optimum choices: low insertion loss, fast response, low control voltage, and reliability. There are a lot of approaches in the microstrip antenna design to achieve frequency reconfigurability. In [8], the authors firstly present the designs of four subpatches with five frequency bands. Next, by integrating four varactor diodes on each subpatch, the frequency band can be independently controlled to achieve frequency reconfigurability. The compact size of 60 $\times 60 \times 40.8 \mathrm{~mm}$ antenna provides dual frequency band around $2.55 \mathrm{GHz}$ and $5.25 \mathrm{GHz}$ with diverse patterns [9]. Another paper [10] shows that, by adjusting the PIN diodes switch on the radiating elements, the proposed antenna can be operated in PIFA for GSM900 (ON mode) or cover the frequencies for GSM1800, GSM1900, and UMTS bands during the OFF mode. The design of annular slot antenna is studied in [1] and the authors introduce an antenna that has two frequency reconfigurabilities, either at $2.4 \mathrm{GHz}$ or at $5.2 \mathrm{GHz}$. A reconfigurable stacked microstrip antenna has been introduced in [11] and the antenna can operate at 


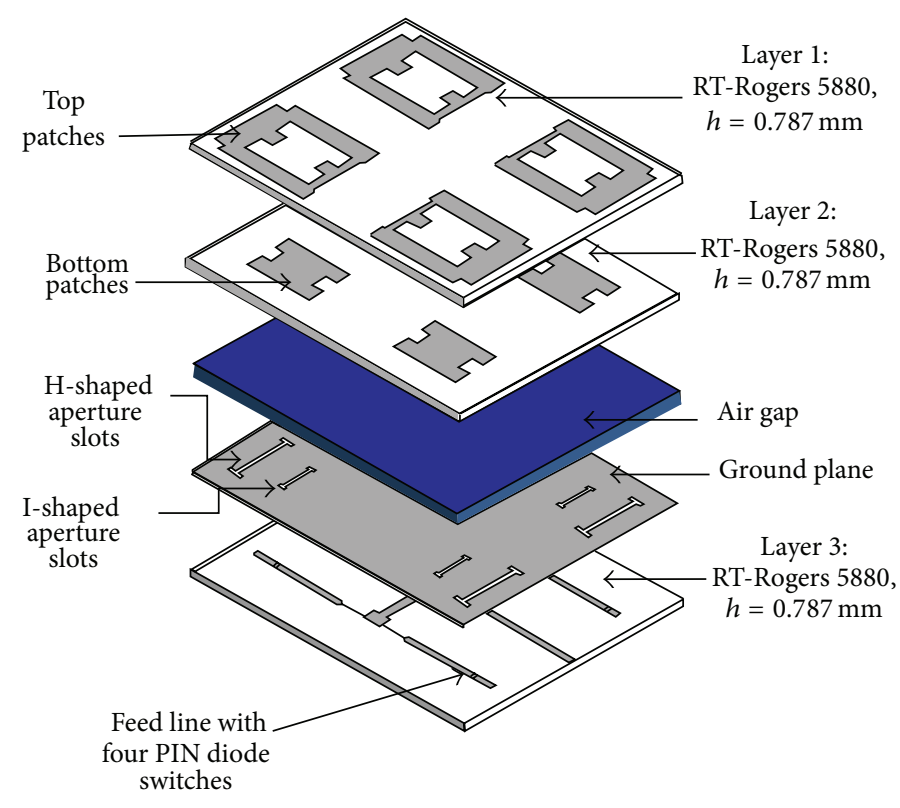

(a)

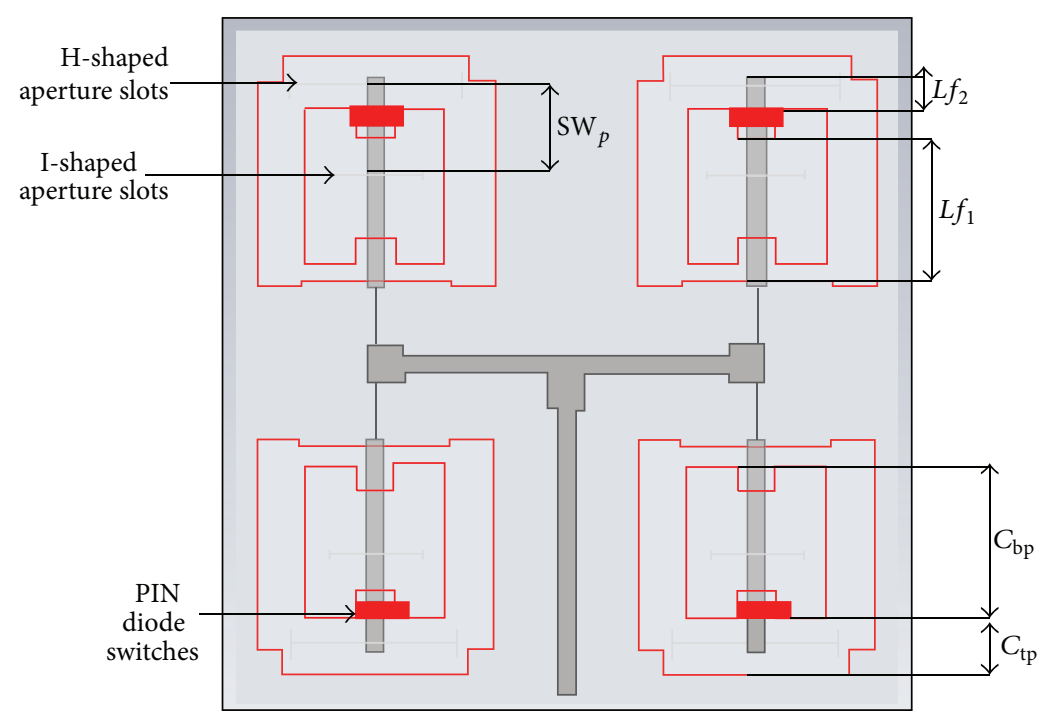

(b)

FIgURE 1: The geometry of the proposed antenna in (a) 3D view and (b) 1-plane view.

two different frequencies: upper frequency $\left(f_{u}\right)$ and lower frequency $\left(f_{l}\right)$ with various bandwidths, patterns, and polarization values. However, research works have been done on the design of frequency-reconfigurable antenna by using stacked substrate. This could be due to the complexity in designing the structure.

Therefore, the aim of this paper is to design a frequencyreconfigurable microstrip antenna by using a combination of a stacked patch array and an aperture-coupled feeding technique. Moreover, a new coupling method in an aperturecoupled technique is implemented to achieve the frequency reconfigurability. By using the same antenna, two different operating frequencies, either $2.6 \mathrm{GHz}$ (LTE application on band 7) or $3.5 \mathrm{GHz}$ (WiMAX), are achieved by configuring the PIN diodes switches on the feed line.

\section{Antenna Configuration and Design Procedure}

Figure 1(a) shows the geometry of the proposed antenna in $3 \mathrm{D}$ view. The antenna is composed of three substrate layers (RT-Rogers 5880) with dielectric constant, $\varepsilon r=2.2$, tangent loss, $\delta=0.0009$, and the thickness, $h=0.787 \mathrm{~mm}$ each. The air gap structure with thickness $h=3 \mathrm{~mm}$ is added between the substrate layer 3 and substrate layer 2 to enhance the gain performance. Besides that, the aperture-coupled technique is used to reduce the spurious radiation pattern from the feed line and the radiating layers. The radiating elements of $2 \times 2$ structures have been etched on top of substrate layer 1 and substrate layer 2, known as top patches and bottom patches, respectively. Basically, the dimensions of the top patches and 


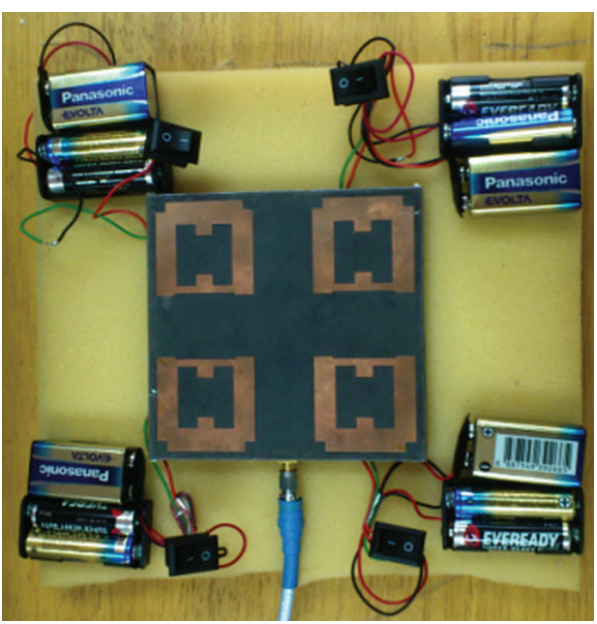

(a)

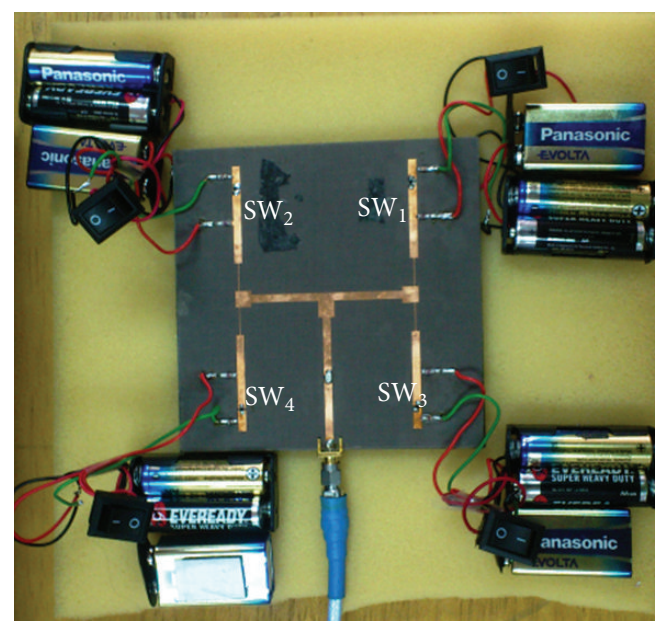

(b)

Figure 2: Photograph of the fabricated antenna: (a) front view antenna on a $120 \mathrm{~mm} \times 120 \mathrm{~mm}$; (b) back view: the feed line integrated with the switching circuit components.

bottom patches are based on $3.5 \mathrm{GHz}$ and $2.6 \mathrm{GHz}$ frequency. Next, the ground is located on the front view of the substrate layer 3. It consists of four sets of two different aperture slots, which are I-shaped and $\mathrm{H}$-shaped aperture slots. To give maximum coupling effects, the aperture slot positions are based on the bottom patches (layer 2) and top patches (layer 1), respectively, that is, in between the length of $C_{\mathrm{bp}}$ and $C_{\mathrm{tp}}$ (Figure 1(b)). In this design, the I-shaped aperture slots are used to radiate the waves to activate the bottom patches, while the $\mathrm{H}$-shaped aperture slots are used to activate the top patches. On the back view of the substrate layer 3, the feed line with four PIN diode switches $\left(\mathrm{SW}_{1}, \mathrm{SW}_{2}, \mathrm{SW}_{3}\right.$, and $\mathrm{SW}_{4}$ ) is integrated in between I-shaped and $\mathrm{H}$-shaped aperture slots. These PIN diode switches divided the feed line length into two lengths, $L_{f 1}$ and $L_{f 2}$. The geometry of the proposed antenna in 1-plane view is shown in Figure 1(b). The prototype of the proposed antenna is fabricated to validate the antenna's performance as shown in Figure 2. The explanation of the proposed antenna working principles to achieve the frequency reconfigurability is explained in Section 3 under the current distributions results.

The frequency reconfigurability of the proposed antenna can be obtained effectively from the PIN diode switch configuration. An electronic switching circuit using the Phillipe PIN diode switches model BAP51-02 is used as the RF switches to form the switching circuit. In this design, the Philips PIN diode switch is inserted in between the two transmission lines on the feed line $\left(L_{f 1}\right.$ and $\left.L_{f 2}\right)$. The Advanced Design System (ADS) software is used to design, simulate, and validate the performance of this switching circuit. Figure 3(a) shows the equivalent switching circuit to represent four PIN diode switches for the proposed antenna. The circuit consists of the passive components including eight inductors $(22 \mathrm{nH})$, one capacitor $(110 \mathrm{pF})$, and four resistors $(150 \Omega)$. Refer to the feed line layout in Figure 3(b). The capacitor is used to prevent the DC signal from flowing to the main feed line or to the SMA connector. However, the capacitor allows the RF current to pass through towards the feed line network, while the eight inductors are used as RF chokes to provide a low impedance for DC. The biasing voltage of $12 \mathrm{~V}(\mathrm{ON}$ mode) is connected to a $150 \Omega$ resistor to limit the current flow to each PIN diode switch, while, in reverse mode, a $0 \mathrm{~V}$ (OFF mode) is supplied. The simulation results using the PIN diode equivalent switching circuits during the $\mathrm{ON}$ mode and OFF mode are presented in Figure 4. When the circuit is supplied with $12 \mathrm{~V}$, Port $1\left(S_{11}\right)$ is in a perfect matching condition and it allows all the signals to pass through to Port $2\left(S_{21}\right)$, Port $3\left(S_{31}\right)$, Port $4\left(S_{41}\right)$, and Port $5\left(S_{51}\right)$. Thus, when in the ON mode, the $S_{11}$ is resonant at $2.6 \mathrm{GHz}$ with $-26.57 \mathrm{~dB}$ while $S_{21}$, $S_{31}, S_{41}$, and $S_{51}$ are constant at $-3.5 \mathrm{~dB}$. However, when the switch is in OFF mode, Port 1 will reflect all the signals and no signals are allowed to pass through to other ports. Therefore, in this mode, the $S_{11}$ is equal to $-0.01 \mathrm{~dB}$ while the other ports are equal to $-53.63 \mathrm{~dB}$ at $3.5 \mathrm{GHz}$. This result proves that the switching circuit can be applied in the proposed antenna.

\section{Simulation and Measurements Results}

3.1. Effects of H-Shaped Aperture Slots (ON Mode). In the conventional methods, there is only single aperture slot to radiate the waves to the radiating elements (on layer two or more) and couple the energy with the feed line. In this research, an aperture-coupled technique has been modified, where the ground of the proposed antenna consists of two different shapes of aperture slots. The purposes of the aperture slots are used to control the activation of the selected radiating elements at different layers. Therefore, at the first stage of designing the proposed antenna, the ON mode configuration is considered and only one aperture slot (I-shaped) has been implemented on the ground. Then, the simulation analysis has been carried out to study the results of the operating frequency. Figure 5 clearly shows that when the proposed antenna only has one aperture slot (I-shaped), the antenna is resonant at $3.2 \mathrm{GHz}$. Therefore, another $\mathrm{H}$-shaped 


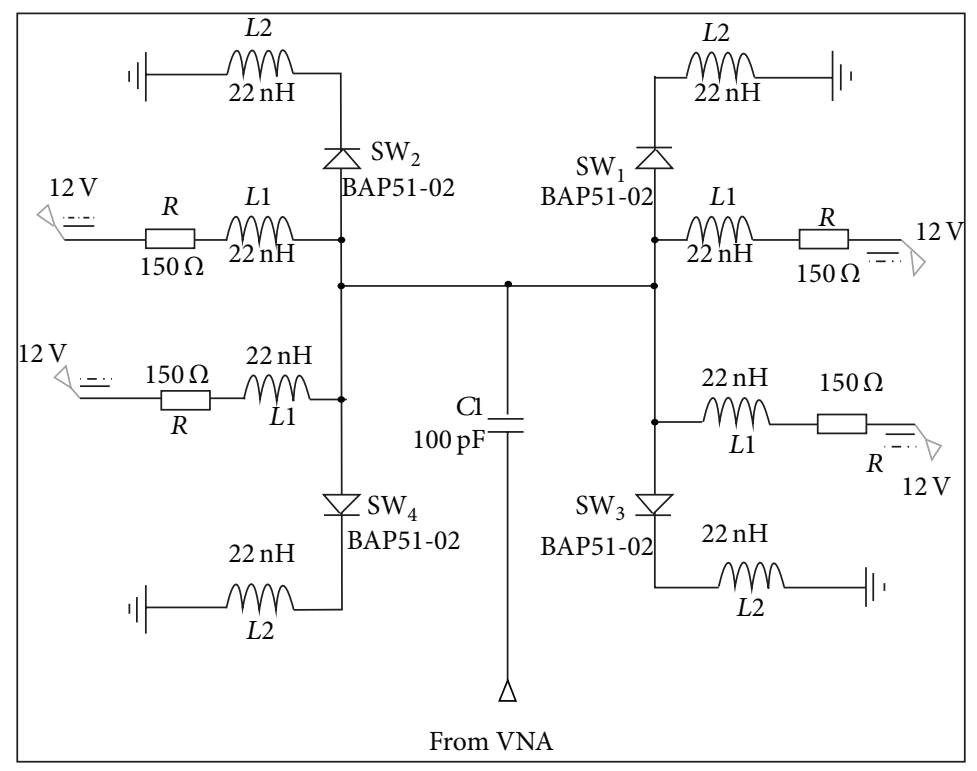

(a)

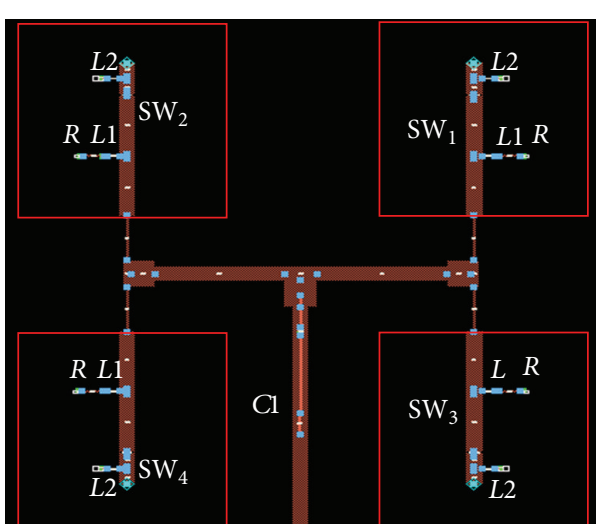

(b)

FIgURE 3: (a) The basic equivalent switching circuit; (b) back view: the feed line layout integrated with the switching circuit component in ADS software.

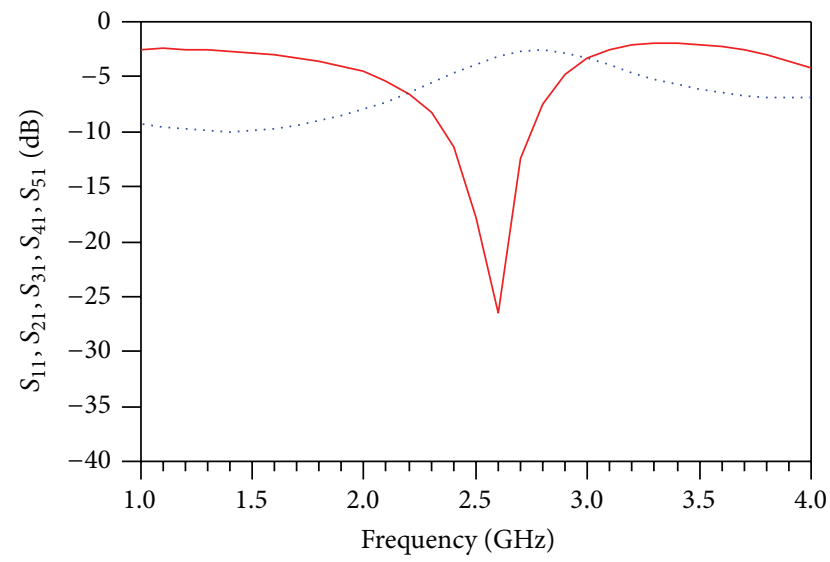

- $S_{11}$ versus frequency

...... $S_{21}, S_{31}, S_{41}, S_{51}$ versus frequency

(a)

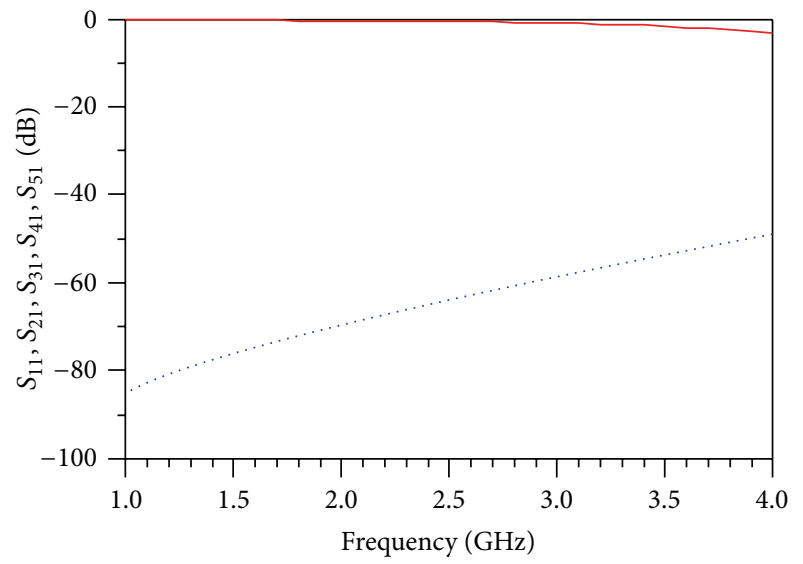

- $S_{11}$ versus frequency $S_{21}, S_{31}, S_{41}, S_{51}$ versus frequency

(b)

FIGURE 4: Simulated results of $S_{11}, S_{21}, S_{31}, S_{41}$, and $S_{51}(\mathrm{~dB})$ versus frequency $(\mathrm{GHz})$ for the equivalent switching circuit when all the PIN diode switches are in (a) ON mode and (b) OFF mode.

aperture slot with a dimension of $32 \times 54 \mathrm{~mm}$ is added on the ground. As shown in Figure 5, the antenna added with $\mathrm{H}$ shaped aperture slot is resonant exactly at $2.6 \mathrm{GHz}$ for longterm evolution (LTE) application.

\subsection{Effects of the PIN Diode Switches Position (OFF Mode).} According to the $\mathrm{ON}$ mode results, now the proposed antenna has two aperture slots on the ground, I-shaped and $\mathrm{H}$-shaped aperture slots. Next, to achieve another operating frequency at $3.5 \mathrm{GHz}$, four PIN diode switches are integrated on the feed line networks. The PIN diode switches are located in between I-shaped and $\mathrm{H}$-shaped aperture slots referring to the ground, labelled as $\mathrm{SW}_{p}$. As illustrated in Figure 6, the PIN diode switch is varied along the $\mathrm{SW}_{p}$, from $2 \mathrm{~mm}$ to $12 \mathrm{~mm}$. It can be observed that the position of the PIN diode switch causes all the frequencies to be resonant at higher frequencies, that is, more than $3.0 \mathrm{GHz}$. Therefore, the simulation result of $\mathrm{SW}_{p}=8 \mathrm{~mm}$ is chosen as it is exactly resonant at $3.5 \mathrm{GHz}$ with good impedance matching of $-48.5 \mathrm{~dB}$. This proves that once the PIN diode switch is 


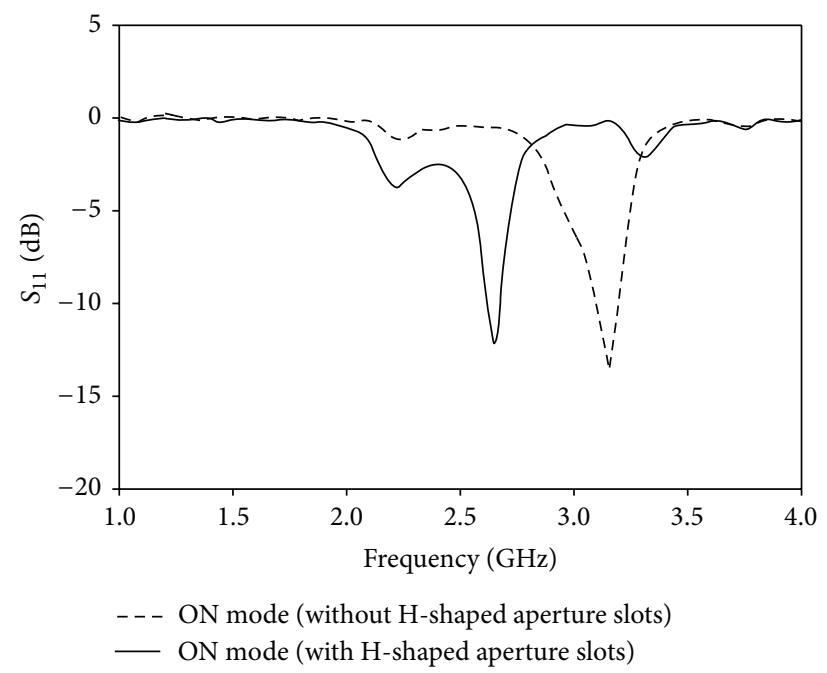

FIGURE 5: Effects of $\mathrm{H}$-shaped aperture slots on $S_{11}$ in ON mode configuration.

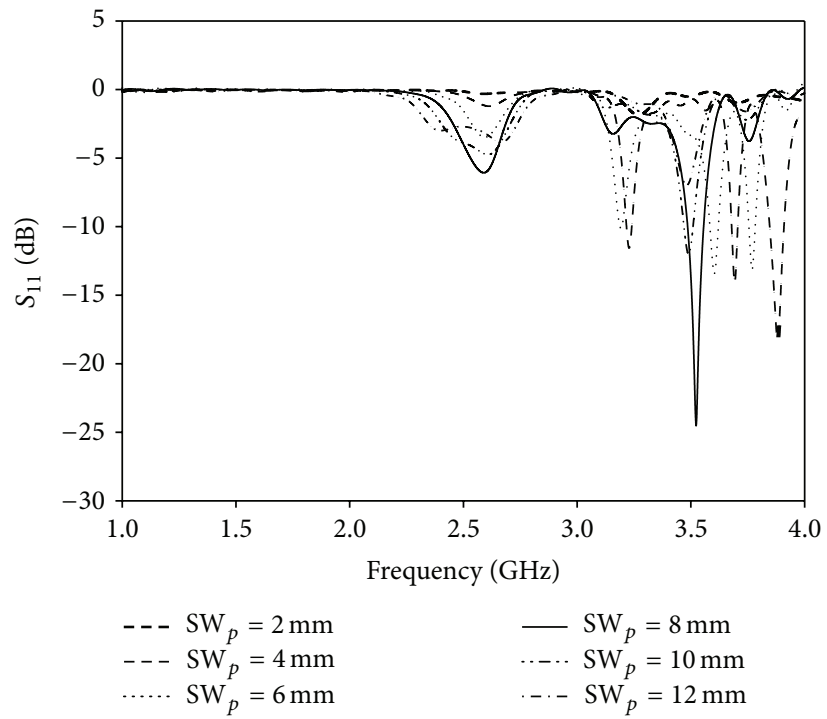

FIgURE 6: Effects of $S W_{p}$ on $S_{11}$ in OFF mode configuration.

in OFF mode, only the bottom patch radiating element is activated, while the top patch acts as the parasitic element and ensures the antenna will be operated at the higher frequency.

3.3. Impedance Bandwidth and Return Losses. To validate the antenna's performance, the impedance bandwidth $\left(S_{11}<\right.$ $-10 \mathrm{~dB})$ and the experimental return losses between simulation and measurement have been analyzed. The CST Microwave Studio software is used to test the proposed antenna for both ON mode and OFF mode. Figure 7(a) shows that the proposed antenna is capable of operating at 2.6 GHz with the bandwidth of $69.5 \mathrm{MHz}$ and $83.0 \mathrm{MHz}$ for the simulation and measurement results. As for return loss results, the measured results show a shift to $2.55 \mathrm{GHz}$ with $-21.76 \mathrm{~dB}$, compared to the simulated results. The measured results in Figure 7(b) show that the antenna is obtained at the frequency of $3.49 \mathrm{GHz}$ when all the PIN diode switches are in OFF mode. The results of impedance bandwidth are equal to $76.5 \mathrm{MHz}$ and $79.3 \mathrm{MHz}$, respectively, between simulation and measurement. Meanwhile, the return losses show better agreement between simulation and measurement. Both results prove that the antenna has good performance both in $\mathrm{ON}$ and OFF modes.

3.4. Current Distributions. The current distribution of the proposed antenna is controlled by the PIN diode switch configuration mode. In this research, only two cases are considered, that is, when all the PIN diode switches are in $\mathrm{ON}$ mode and when all the PIN diode switches are in OFF mode. These PIN diode switches are located on the feed line, between $L_{f 1}$ and $L_{f 2}$ as shown in Figure 1(b). Figure 8 shows the simulated current distributions at each layer in different switching modes. In the $\mathrm{ON}$ mode, the feed line lengths of 


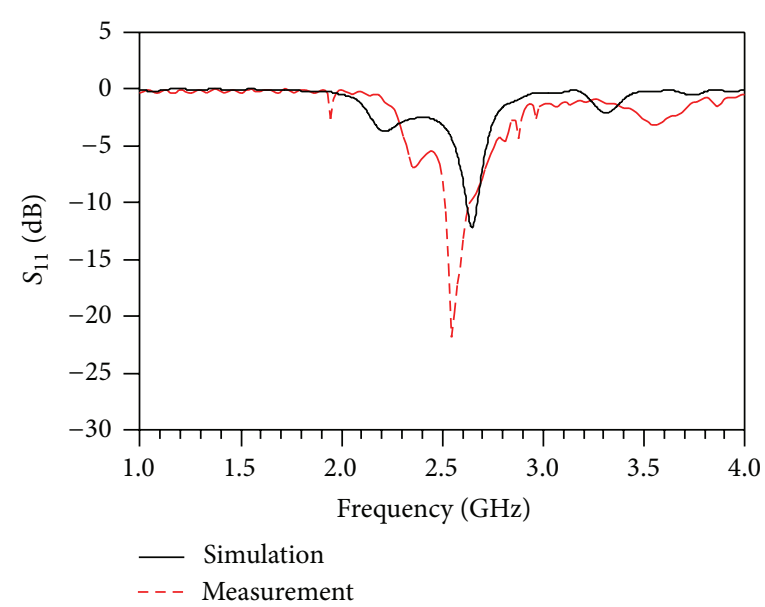

(a)

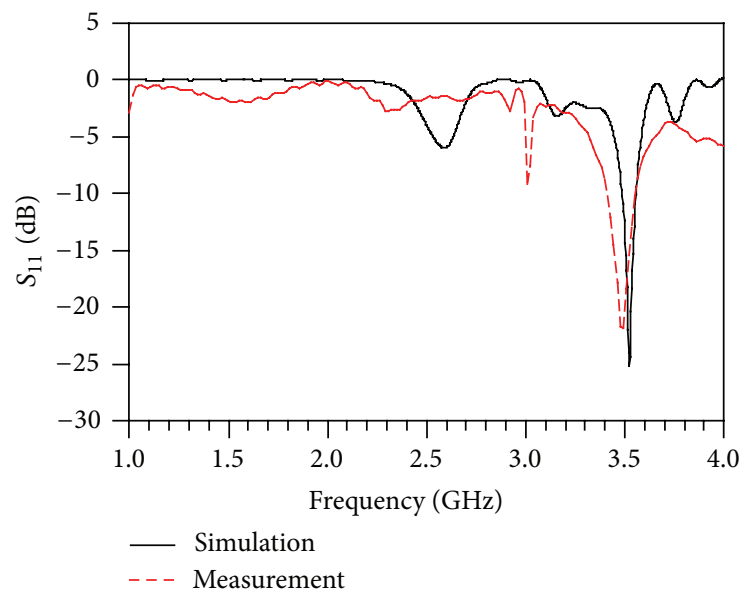

(b)

FIGURE 7: Return losses of the proposed antenna: (a) ON mode and (b) OFF mode.

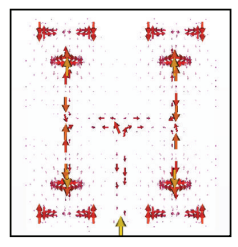

Layer 3: feed line

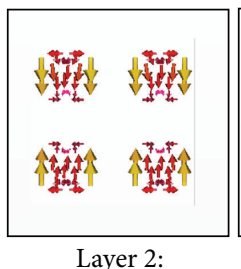

bottom patches

(a)



top patches



Layer 3: feed line

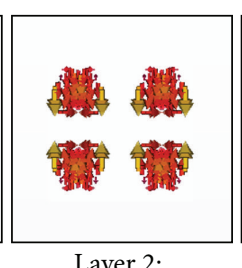

Layer $2:$
bottom patches

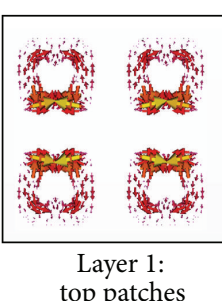

top patches (b)

FIGURE 8: Simulated current distributions at each layer during (a) ON mode and (b) OFF mode.

$L_{f 1}$ and $L_{f 2}$ are connected to each other, thus generating the major signal to activate all the I-shaped and $\mathrm{H}$-shaped aperture slots in the ground, as shown in Figure 8(a). Next, the current from I-shaped aperture slots will radiate and pass through to the bottom patches on layer 2, while the current from $\mathrm{H}$-shaped aperture slots will radiate to the top patches on layer 1. As explained, we can see that the current distributions radiate equally around top and bottom patches. At this stage, both top and bottom patches will be combined, thus resulting in larger patches. As a result, the antenna is resonant at low frequency of $2.6 \mathrm{GHz}$. In contrast, when all PIN diode switches are in OFF mode, the feed line lengths of $L_{f 1}$ and $L_{f 2}$ are disconnected from each other. Therefore, the signal from $L_{f 1}$ will radiate to I-shaped aperture slots while the signal from $L_{f 2}$ does not radiate to the $\mathrm{H}$-shaped aperture slots. However, as shown in Figure 8(b), we can see that there is still some current around the $\mathrm{H}$-shaped aperture-coupled antenna. As a result, the current from the I-shaped aperture slots strongly radiates to the bottom patches. Meanwhile, the current around the top patches acts as a parasitic element. The activation of the bottom patches allows the antenna to operate at a high resonant frequency of $3.5 \mathrm{GHz}$ with higher gain compared to ON mode. Based on this concept, the frequency reconfigurability can be obtained by controlling the coupling on the ground.
3.5. E-Plane and H-Plane Radiation Patterns. As illustrated in Figure 9, the radiation patterns of the proposed antenna are measured and simulated in two planes-either in $H$-plane $\left(x-z\right.$ direction) with phi $=0^{\circ}$ or in $E$-plane ( $y-z$ direction) with phi $=90^{\circ}$. Figure 9 (a) shows the simulated and measured the radiation patterns in $\mathrm{ON}$ mode at $2.6 \mathrm{GHz}$, while Figure 9(b) in OFF mode. Based on both results, there is a good agreement between the simulation and measurement results. However, some minor discrepancies that occurred during the measured results are due to a few factors such as the effects of the switching circuit components on the feed line and the complexity during the gluing of all the substrate layers to get the perfect alignment in each layer. These radiation patterns describe that the proposed antenna is directed to $32^{\circ}$ with $76.5 \mathrm{MHz}$ bandwidth in ON mode, while, in OFF mode, the proposed antenna is directed to $28^{\circ}$ with $69.5 \mathrm{MHz}$. Besides that, the HPBW in ON mode is $37.3^{\circ}$ and in OFF mode is $35.0^{\circ}$. Moreover, the gain is equal to $9.415 \mathrm{dBi}$ and $10.49 \mathrm{dBi}$ during the ON or OFF mode, respectively (Figure 10).

\section{Practical Indoor Antenna Measurement}

The proposed antenna, known as an antenna under test (AUT), acts as a transmitter $\left(T_{x}\right)$ antenna to test the capability of the antenna to transmit the signal to the receiver $\left(R_{x}\right)$ and 


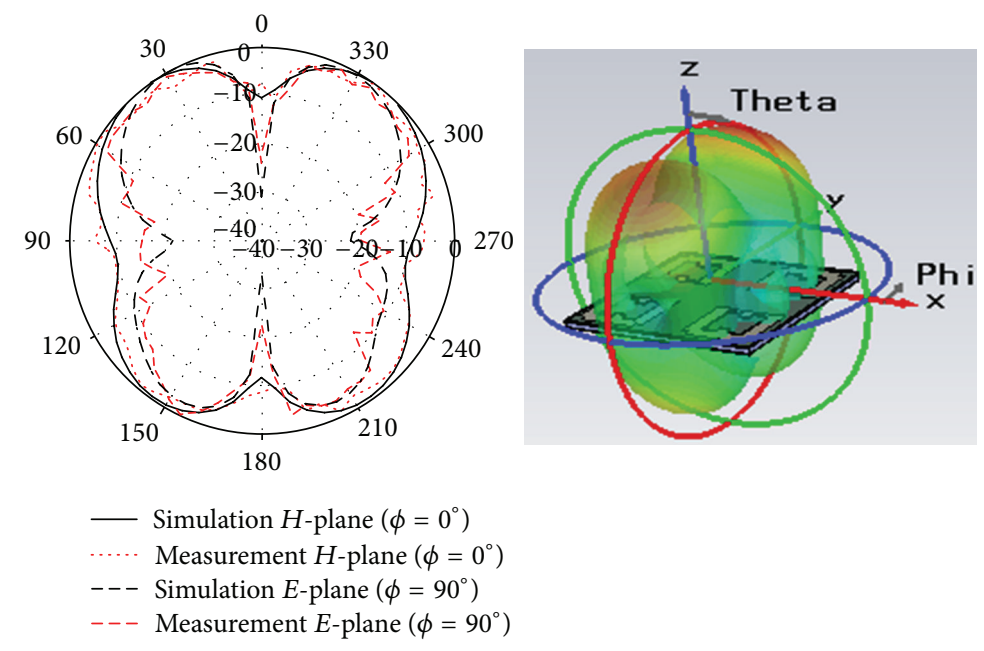

(a)
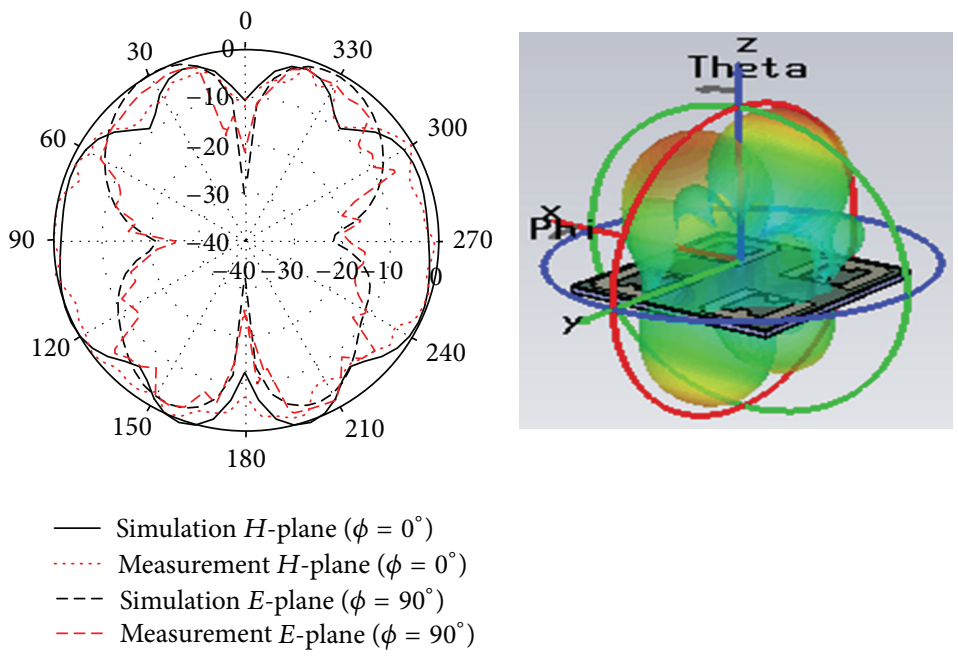

(b)

FIGURE 9: Radiation patterns of the proposed antenna in polar plot and 3D view during (a) ON mode and (b) OFF mode.

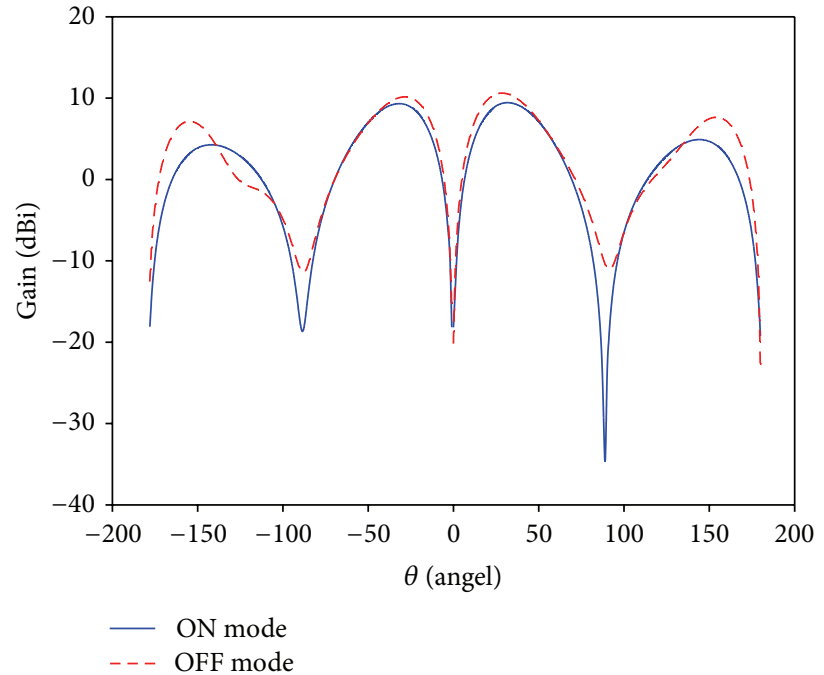

FIgURE 10: Simulated gains during (a) ON mode at $2.6 \mathrm{GHz}$ and (b) OFF mode at $3.5 \mathrm{GHz}$. 


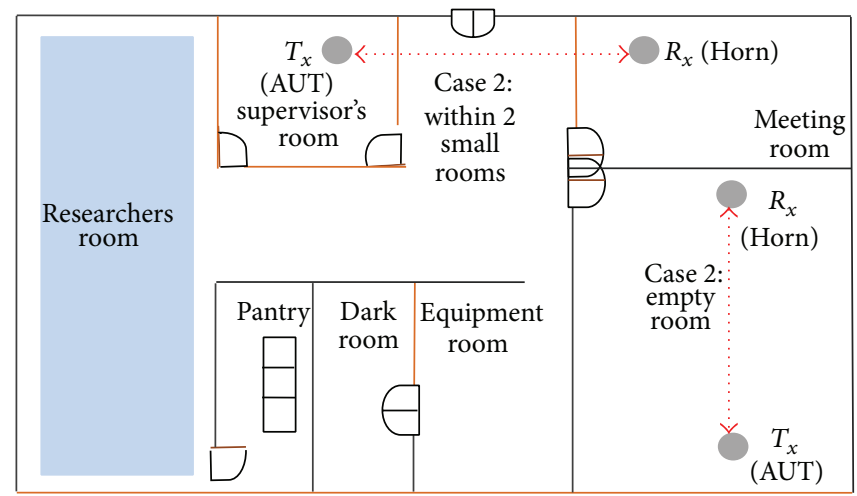

Figure 11: The plan of the empty room and within two small rooms in the Antenna Research Group lab, where the PL and $P_{r}$ were carried out.

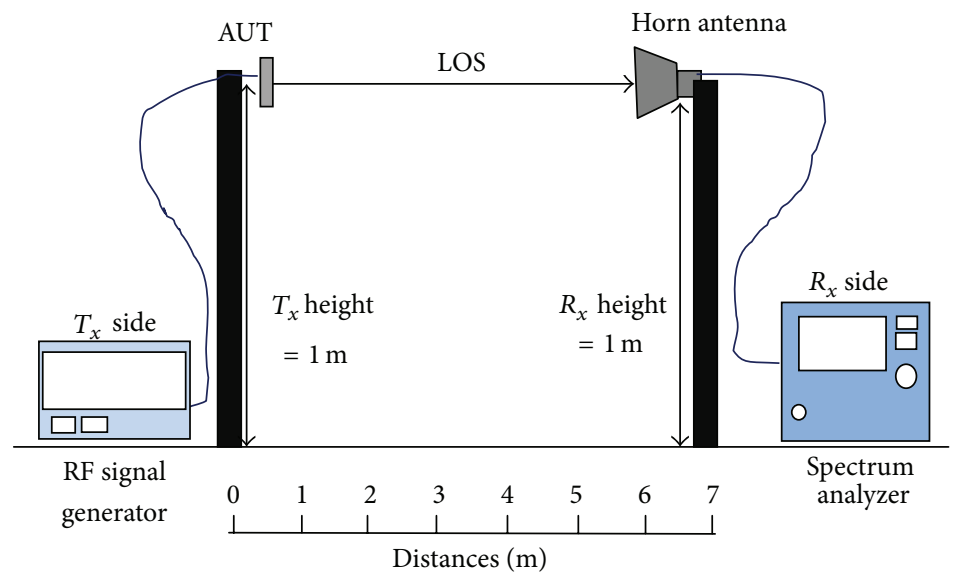

FIGURE 12: The practical antenna measurement setup.

to verify the distance based on the power transmit $\left(P_{t}\right)$ signal. Therefore, the power received $\left(P_{r}\right)$ signal measurement is carried out at the $R_{x}$ side when the distances between the $T_{x}$ and $R_{x}$ vary from $1 \mathrm{~m}$ to $7 \mathrm{~m}$. In this work, the measurement was conducted in two conditions, which are in an empty room $(8.95 \mathrm{~m} \times 6.17 \mathrm{~m})$ and within two small rooms (between meeting room and supervisor's room) with the same power transmit $\left(P_{t}\right)$. All the rooms were located in the Antenna Research Group lab (Figure 11). Firstly, the practical indoor propagation was carried out in an empty room with the minimum $P_{t}$ of $0 \mathrm{dBm}$ supplied to the AUT so the whole area of the empty room was covered. However, at the distance of $7 \mathrm{~m}$, no power received $\left(P_{r}\right)$ signal was detected on the $R_{x}$ side. This finding proves that, with the minimum of $P_{t}$ at $0 \mathrm{dBm}$, the AUT has the capability to transmit the signal to the $R_{x}$ side with maximum distance of $6 \mathrm{~m}$ in an empty room. During the indoor measurements, the actual frequencies from the return loss experimental results, namely, $2.55 \mathrm{GHz}$ (ON mode) and $3.49 \mathrm{GHz}$ (OFF mode), were used to inject the signal at the RF signal generator. The AUT measurement was carried out at the $28^{\circ}$ and $32^{\circ}$ during the $\mathrm{ON}$ or OFF mode, respectively.

The indoor practical antenna measurement setup is shown in Figure 12. Both AUT and $R_{x}$ positions at a height of $1 \mathrm{~m}$ must be placed face-to-face and aligned towards each other to obtain a line-of-sight (LOS) condition. At the $T_{x}$ side, the signal generator with Wiltron $6647 \mathrm{~B}$ model $(10 \mathrm{MHz}$ to $20 \mathrm{GHz}$ ) was used to inject the RF signal to the AUT, while the equipment at the $R_{x}$ side was a receiving antenna (Horn antenna with ED200C model) connected to the spectrum analyzer (Advantest U3751).

Theoretically, the path loss (PL) versus the distance between the $T_{x}$ and $R_{x}$ is described in the ground reflection (two-ray) propagation model [12], as formula shown in (1). Consider

$$
\begin{aligned}
\mathrm{PL}= & 32.44+[20 \log d]+[20 \log f]-G_{T}-G_{R} \\
& +\left[T_{\text {other losses }}\right],
\end{aligned}
$$

where $d$ is the distance $(\mathrm{km}), f$ is the frequency $(\mathrm{MHz})$, $G_{T}$ is the transmitter (AUT) gain $(\mathrm{dBi}), G_{R}$ is the receiver gain $(\mathrm{dBi})$, and $T_{\text {Other losses }}$ includes the floor, wall, and glass coefficient, which are defined as $T_{\text {floor }}=13 \mathrm{~dB}, T_{\text {wall }}=2.2 \mathrm{~dB}$, and $T_{\text {glass }}=0.25 \mathrm{~dB}$, respectively [12]. The $G_{T}$ gain value refers to the AUT during the simulation and the $G_{R}$ gain value refers to the Horn antenna $\left(R_{x}\right)$ with $10 \mathrm{dBi}$ gain. In this work, during the measurement in the empty room, only the floor loss $(13 \mathrm{~dB})$ was considered, while, within the two rooms, the floor loss included the floor, two walls, and two glasses, thus making up other losses equal to $17.9 \mathrm{~dB}$. Next, 




(a)

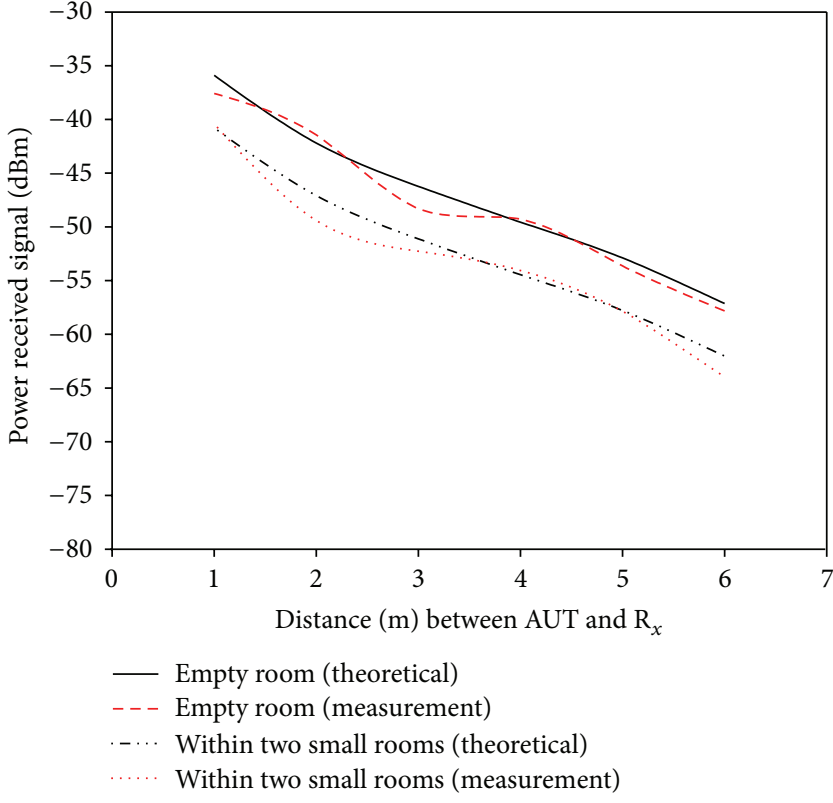

(b)

FIGURE 13: Comparison between theoretical and measurement results of the distance between AUT and $R_{x}$ (unit: $\mathrm{m}$ ) in an empty room and within two rooms during (a) ON mode and (b) OFF mode.

the $P_{r}$ is determined following (2) and the theoretical results will be compared with the measurement results in an empty room or two small rooms as follows:

$$
\mathrm{PL}=10 \log \left[\frac{P_{t}}{P_{r}}\right] .
$$

Figures 13(a) and 13(b) show the power received signal comparison between theoretical and measurement results, in an empty room and within two small rooms, during ON and OFF modes. The $P_{r}$ values between the theoretical and measured results either in an empty room or within two rooms are rather similar. As shown in both figures, when the distance between $T_{x}$ and $R_{x}$ increases, the $P_{r}$ signal decreases. The figures also show that when the same powers are used to transmit a signal between rooms, the received signal is lower compared to the received signal in an empty room. These results clearly show that when there is an obstacle, the signal transmission performance will be reduced. From the experimental results of this work, it is proven that the antenna can perform as a transmitter as the signal can be transmitted to the receiver side, either with or without obstacle. The AUT can cover a minimum distance of $6 \mathrm{~m}$ with minimum $P_{t}$ equal to $0 \mathrm{dBm}$ or 0.001 Watt. However, if the $P_{t}$ is supplied with more than a $0 \mathrm{dBm}$ power signal, the AUT has a capability to transmit the signal further.

\section{Conclusion}

In summary, the proposed antenna with a unique structure of a frequency-reconfigurable microstrip antenna has been presented. The proposed antenna used a combination of an aperture-coupled technique and stacked patch technology. In this design, the $2 \times 2$ radiating elements of top and bottom patches are etched on a different substrate layer to indicate different operating frequencies. New coupling methods have been implemented in aperture-coupled technique to control the activation of the selected aperture slots on the ground to radiate the waves to the particular patches and eventually to achieve frequency reconfigurability. By controlling all the PIN diode switches on the feed line, the proposed antenna has a capability to operate at two different operating frequencies, either at $2.6 \mathrm{GHz}$ frequency in $\mathrm{ON}$ mode or at $3.5 \mathrm{GHz}$ frequency in OFF mode. On top of that, the air gap with low dielectric constants, that is, 1.00 , gives an advantage as the waves from the activated aperture slots on the ground are free to travel and radiate to particular radiating patches without passing through the substrate material layers. Moreover, the gain and bandwidth of the proposed antenna are considerably higher compared to using a single layer substrate as found in other antennas. It is confirmed that the antenna achieves a good agreement with the simulation. The results from this research have a great potential in wireless communication and can be used in long-term evolution (LTE) for band 7 and WiMAX applications, especially in Malaysia.

\section{Conflict of Interests}

The authors declare that there is no conflict of interests regarding the publication of this paper.

\section{Acknowledgments}

This work was supported by the Faculty of Electrical Engineering (Antenna Research Group), UiTM, and the Ministry 
of Higher Education (MOHE), Malaysia. The authors also wish to thank the Research Intensive Grant (RIF) 600RMI/DANA 5/3/RIF (189/2012) for the financial aid for this project.

\section{References}

[1] B. A. Cetiner, G. Roqueta Crusats, L. Jofre, and N. Biyikli, "RF MEMS integrated frequency reconfigurable annular slot antenna," IEEE Transactions on Antennas and Propagation, vol. 58, no. 3, pp. 626-632, 2010.

[2] D. Rodrigo and L. Jofre, "Frequency and radiation pattern reconfigurability of a multi-size pixel antenna," IEEE Transactions on Antennas and Propagation, vol. 60, no. 5, pp. 2219-2225, 2012.

[3] S. Muhamud-Kayat, M. T. Ali, M. K. Mohd Salleh, M. H. Mohd Rusli, N. Ramli, and H. Alias, "Truncated rhombus-like slotted antennas with aperture coupling technique," Progress in Electromagnetics Research Letters, vol. 39, pp. 181-198, 2013.

[4] J. Perruisseau-Carrier, "Dual-polarized and polarization-flexible reflective cells with dynamic phase control," IEEE Transactions on Antennas and Propagation, vol. 58, no. 5, pp. 1494-1502, 2010.

[5] F. Ferrero, C. Luxey, R. Staraj, G. Jacquemod, M. Yedlin, and V. Fusco, "A novel quad-polarization agile patch antenna," IEEE Transactions on Antennas and Propagation, vol. 57, no. 5, pp. 1562-1567, 2009.

[6] D. Rodrigo, J. Romeu, S. Capdevila, and L. Jofre, "A figure-ofmerit for pattern reconfigurable antennas," IEEE Transactions on Antennas and Propagation, vol. 61, no. 3, pp. 1448-1453, 2013.

[7] Y.-Y. Bai, S. Xiao, M.-C. Tang, Z.-F. Ding, and B.-Z. Wang, "Wide-angle scanning phased array with pattern reconfigurable elements," IEEE Transactions on Antennas and Propagation, vol. 59, no. 11, pp. 4071-4076, 2011.

[8] H. F. AbuTarboush, R. Nilavalan, S. W. Cheung, and K. M. Nasr, "Compact printed multiband antenna with independent setting suitable for fixed and reconfigurable wireless communication systems," IEEE Transactions on Antennas and Propagation, vol. 60, no. 8, pp. 3867-3874, 2012.

[9] C.-H. Wu and T.-G. Ma, "Self-oscillating semi-ring active integrated antenna with frequency reconfigurability and voltagecontrollability," IEEE Transactions on Antennas and Propagation, vol. 61, no. 7, pp. 3880-3885, 2013.

[10] Y. K. Park and Y. Sung, "A reconfigurable antenna for quad-band mobile handset applications," IEEE Transactions on Antennas and Propagation, vol. 60, no. 6, pp. 3003-3006, 2012.

[11] M. Ali, A. T. M. Sayem, and V. K. Kunda, "A reconfigurable stacked microstrip patch antenna for satellite and terrestrial links," IEEE Transactions on Vehicular Technology, vol. 56, no. 2, pp. 426-435, 2007.

[12] M. I. Jais, M. F. B. Jamlos, M. Jusoh et al., "A novel $2.45 \mathrm{GHz}$ switchable beam textile antenna (Sbta) for outdoor wireless body area network (WBAN) applications," Progress in Electromagnetics Research, vol. 138, pp. 613-627, 2013. 

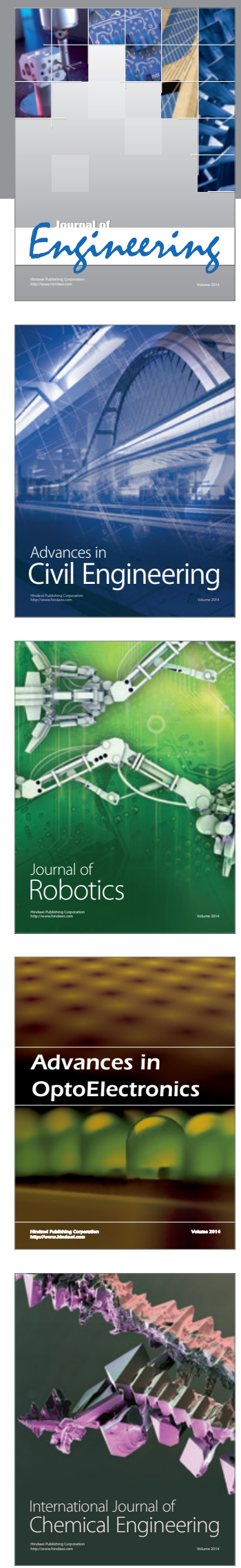

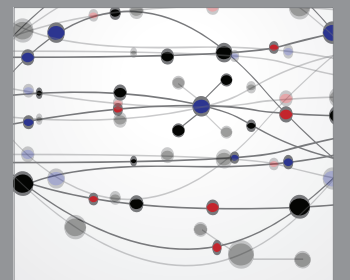

The Scientific World Journal


Submit your manuscripts at http://www.hindawi.com
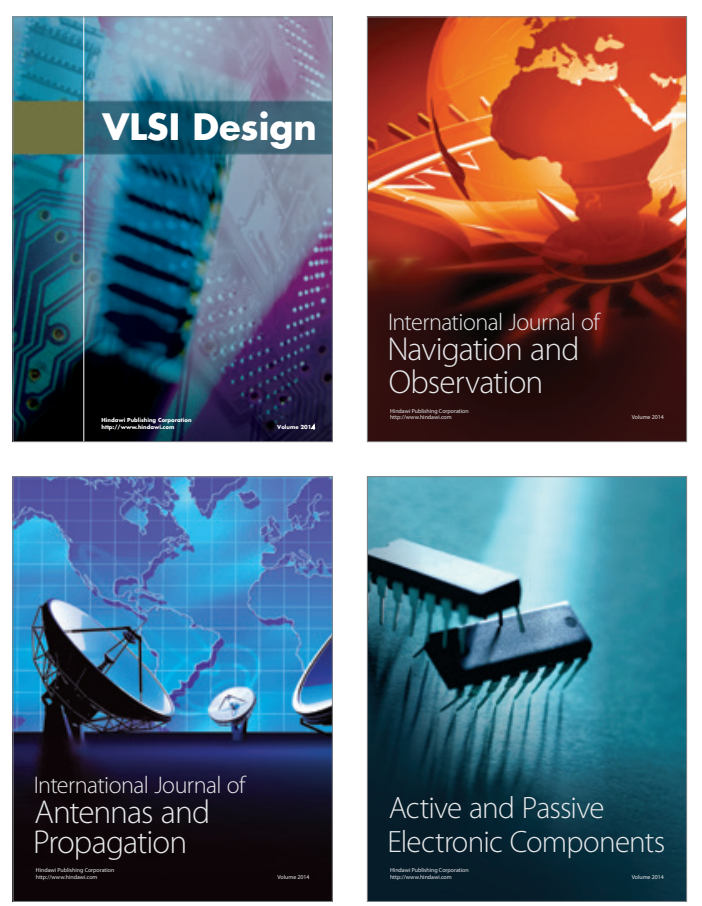
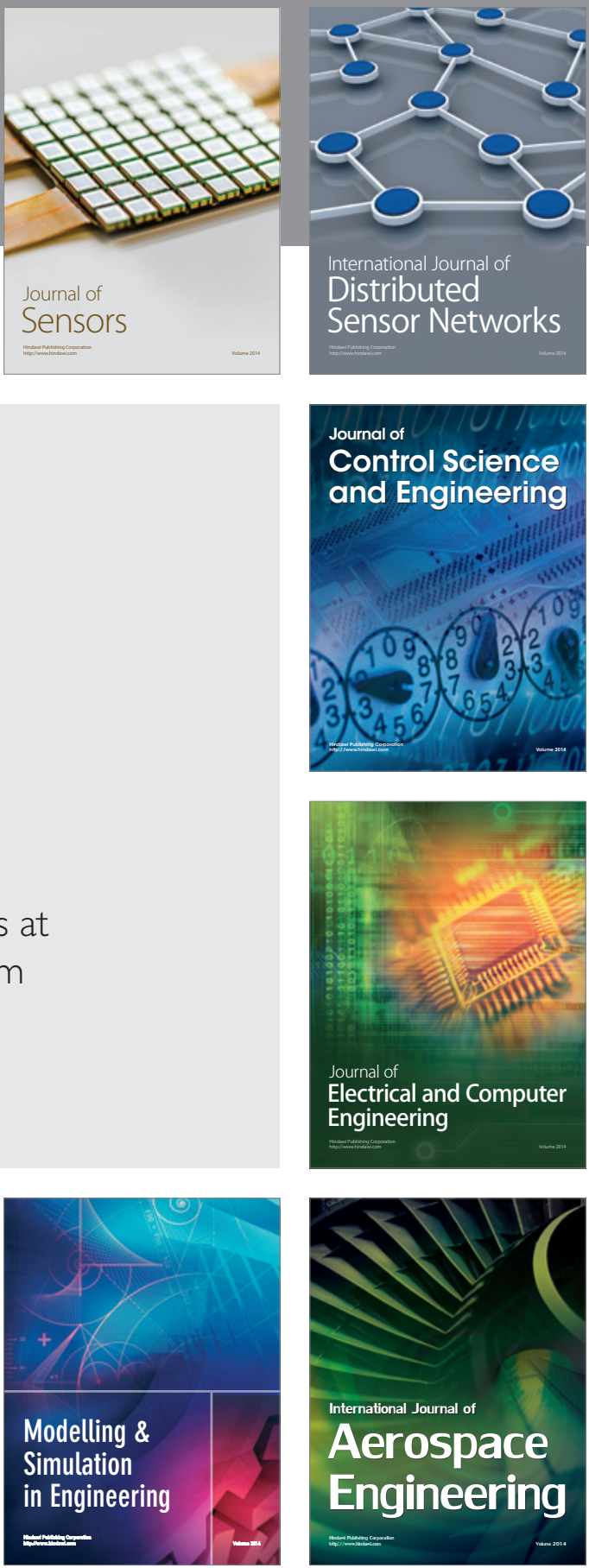

Journal of

Control Science

and Engineering
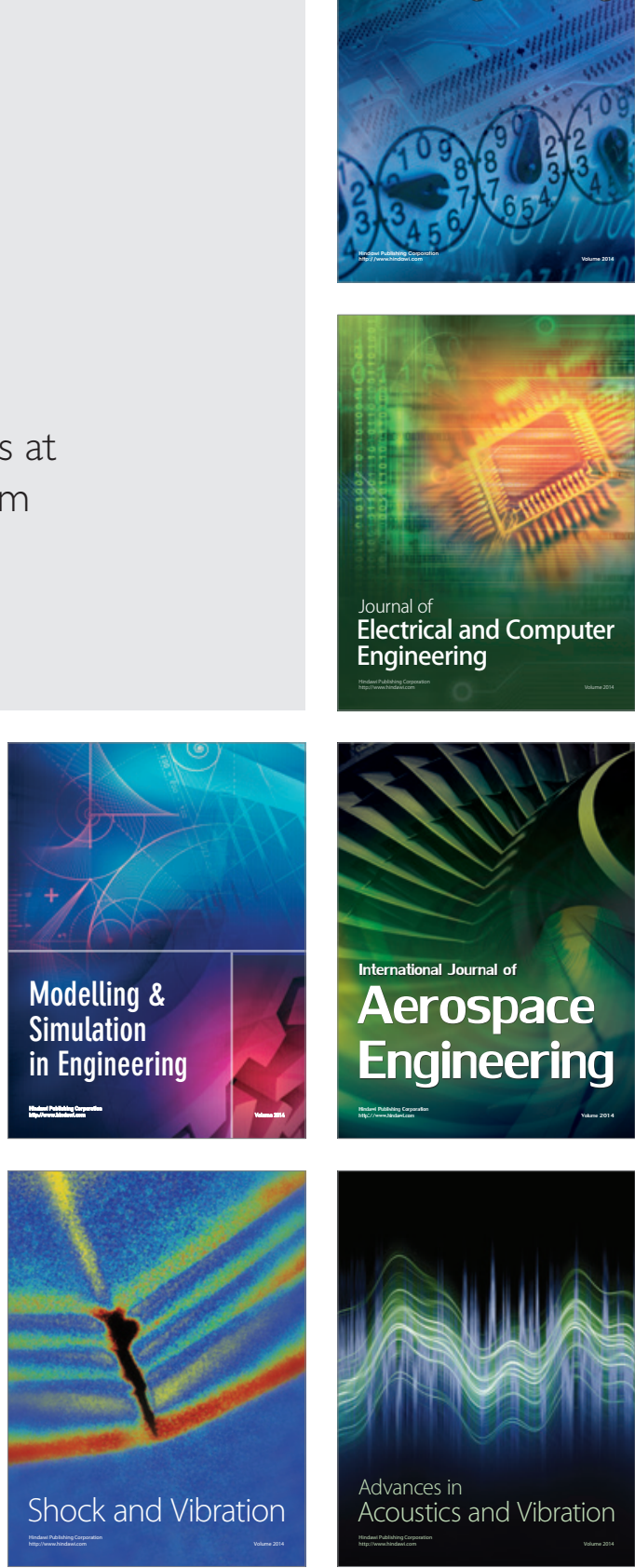